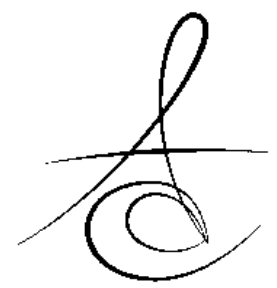

\title{
DENTAL RADYOGRAFİK GÖRÜNTÜLEMEDE ÜÇÜNCÜ BOYUT: BİR LİTERATÜR GÜNCELLEMESİ
}

\section{THIRD DIMENSION IN DENTAL RADIOGRAPHIC IMAGING: A LITERATURE UPDATE}

\author{
Arş. Gör. Nezaket Ezgi ÖZER*
}

Prof. Dr. B.Güniz BAKSI ŞEN*

\author{
Makale Kodu/Article code: 4386 \\ Makale Gönderilme tarihi: 08.05 .2020 \\ Kabul Tarihi: 05.11.2020 \\ DOI : $10.17567 /$ ataunidfd. 821983
}

Nezaket Ezgi Özer: ORCID ID: 0000-0002-5733-0954

\section{öz}

Dentomaksillofasiyal bölgenin üç boyutlu görüntülenmesi ve üç farklı düzlemde kesitsel olarak incelenebilmesine olanak tanıyan Dental Volümetrik Tomografi (DVT)'nin kullanımı, diş hekimliğinin birçok disiplininde yaygınlaşmaktadır. DVT'nin, farkı disiplinleri için değişen kullanım alanları, ne zaman, hangi durumlarda ve hangi çekim parametreleri ile kullanılmasına yönelik kurallar bulunmakta ve her disipline ait bu özel raporlar ilgili birlik ve organizasyonlar tarafından tek tek yayımlanmaktadır. Bu derlemenin amacı; DVT'nin diş hekimliğinin farklı uzmanlık alanları için yayımlanan güncel durum raporlarını bir araya getirmek ve bütün olarak irdelemektir.

Anahtar kelimeler: Konik ışınlı bilgisayarlı tomografi; radyografi, dental görüntüleme

\section{ABSTRACT}

Dental volumetric tomography (DVT) provides three-dimensional and sectional images in three different planes of dentomaxillofacial region and its use becomes increasingly more common in various disciplines of dentistry. Individual associations and organizations published separate position statements for indications, when and how to use DVT for different disciplines of dentistry. The aim of this review article is to compile recent position papers and systematic reviews for current applications and trends of DVT and principles of its use in various dental specialities.

Keywords: Cone-beam computed tomography; radiography, dental imaging

\section{*Ege Üniversitesi, Diș Hekimliği Fakültesi, Ağız, Diș ve Çene Radyolojisi AD, Bornova, İzmir}

Kaynakça Bilgisi: Özer E, Baksı Şen BBG. Dental implantlar etrafında erken dönem marjinal kemik rezorpsiyonunu etkileyen faktörler. Atatürk Üniv Diş Hek Fak Derg 2021; 31: 652-61.

Citation Information: Ozer E, Baksi Sen BBG. Third Dimension in Dental Radiographic Imaging:A Literature Update. J Dent Fac Atatürk Uni 2021; 31: 652-61.

\section{GİRİŞ}

Konik ışınlı bilgisayarlı tomografi (KIBT) olarak da isimlendirilen, dental volümetrik tomografi (DVT) ilk olarak 1982 yılında anjiyografi için geliştirilmiş ve daha sonra 1995 yılında maksillofasiyal bölgenin görüntülenmesi amacıyla diş hekimliği kliniklerine girmiştir. ${ }^{1}$ DVT çekimi, koni şeklinde X-ışını demetinin ve görüntü dedektörünün eş zamanlı olarak hastanın başı çevresinde 180 veya 360 derecelik dönüşü ile gerçekleştirilmektedir. Bu dönüş sonucunda boyutları önceden seçilen bir hacmin bilgisayar yazılımı ile üç farklı kesitte (multiplanar-aksiyel, sagittal ve koronal) görüntülenmesi sağlanmaktadır. ${ }^{2}$
DVT, medikal bilgisayarlı tomografi (BT) ile karşılaştırıldığında daha düşük efektif doz ile daha yüksek çözünürlükte görüntüler sağlamasına rağmen diş hekimliğinde kullanılan iki-boyutlu konvansiyonel radyografi teknikleri ile kıyaslandığında daha yüksek efektif doz ile görüntü oluşturmaktadır. ${ }^{3}$ Bu nedenle DVT çekimi öncesinde mutlaka olası riskler hesaplanarak hastanın tanı ve tedavi planlamasına katkı sağlayabilecek endikasyonlarda kullanılması; ALARA (as low as reasonably archievable) ve ALADA (as low as diagnostically acceptable) ilkeleri göz önünde bulundurularak en düşük doz ile maksimum diyagnostik bilgiye ulaşılması amaçlanmalıdır. 
DVT kullanımının yaygınlaşması, DVT'nin diş hekimliğinde kullanımı için gerekli temel ilkelerin, gerekçelendirmelerin ve optimizasyon stratejilerinin yer aldığı kapsamlı kılavuzların geliştirilmesi ihtiyacını doğurmuştur. Bu amaçla 2008-2011 yılları arasında Avrupa'daki çeşitli merkezlerden diş hekimleri, dental radyologlar, medikal fizikçi ve farklı disiplinlerden uzman diş hekimlerinin dahil olduğu; sonraki yıllarda Avrupa Atom Enerjisi Topluluğu Yedinci Çerçeve Programı tarafından da desteklenen bir araştırma projesi (SEDENTEXCT) hazırlanmıştır. ${ }^{3}$

2011'de SEDENTEXCT'nin "Kanıta Dayalı Kılavuz" başlığı ile yayımladığı kılavuzda; DVT kullanımı ve çekimi ile ilgili uyulması gereken temel ilkeler, radyasyon dozu ve buna bağlı potansiyel riskler ile diş hekimliğinin her disiplini için farklı gerekçelendirme ve yönlendirme kriterleri listelenmiştir.

Diş hekimliğinin hangi disiplininde kullanılacak olursa olsun SEDENTEXCT kılavuzunda temel olarak vurgulanan maddeler;

- DVT çekimi öncesinde her olgu için spesifik olarak yarar/zarar değerlendirmesinin yapılması,

- Sadece tanıya veya tedavi planlamasına katkı sağlayacak durumlarda DVT çekimi reçetelenmesi,

- DVT çekim isteklerinin, anamnez ve klinik muayene olmadan kesinlikle yapılmaması,

- Hastaya ulaşan dozu minimize etmek ve ALADA kurallarına uymak amacıyla, mümkün olan en küçük görüntüme hacminin ve tanısal açıdan yeterli kalitede görüntü eldesini sağlayacak ışınlama parametrelerinin tercih edilmesi vurgulanmıştır. ${ }^{3}$

SEDENTEXCT'nin yayımlamış olduğu kılavuzun her 5 yılda bir güncellenmesi planlanmıştır ancak finansman desteği sağlanamadığı için bu güncelleme gerçekleştirilememiştir. Bunun yerine diş hekimliğinin farklı disiplinlerinde durum güncelleme raporları formatında yeni kılavuzlar oluşturularak güncel literatürler ışı̆ında DVT kullanımına yönelik kurallar yenilenmektedir. Bu derlemenin amacı; diş hekimliğinin farklı disiplinleri için son yıllarda yayımlanan durum raporlarını bir araya getirerek DVT'nin diş hekimliğinin farklı disiplinlerdeki kullanım alanlarını ve kurallarını güncellemektir.

\section{İMPLANTOLOJİ}

Mevcut kemik hacmi ve yapısının değerlendirilebilmesi, operasyon bölgesine yakın önemli anatomik komşulukların saptanması ve ölçüm doğruluğunun diğer görüntüleme yöntemlerine kıyasla daha yüksek olması gibi önemli özellikleri sayesinde DVT, diş hekim- liğinde en sık olarak implant planlaması için kullanılmaktadır.

2012 yılında Uluslararası İmplantolojistler Derneği'nin yayımladığı konsensüs raporunda; DVT'nin kemik ögmentasyonu gibi rekonstrüktif cerrahi işlemlerin planlandığı olgularda, kemik miktarının yetersiz olduğu ve kritik anatomik komşuluk varlığında, mümkün olan en küçük hacim seçilerek kullanılması önerilmektedir. ${ }^{4}$ Adı geçen raporda DVT'nin implant planlaması amacıyla aşağıdaki kriterler doğrultusunda kullanılması önerilmektedir:

- 2 boyutlu konvansiyonel radyografi yöntemlerinin yetersiz olduğu bilgisayar destekli planlama gerektiren olgular,

- Estetik bölgede implant planlaması,

- Kemik grefti planlaması ve greft alanının değerlendirmesi,

- Travma hikayesi veya şüphesi olan hastalarda çenelerin değerlendirilmesi,

- Maksillofasiyal lezyonlar ve gelişimsel defektlerin değerlendirilmesi,

- İmplant uygulamaları sonrasında gelişen komplikasyonların tanısı ve değerlendirilmesi. ${ }^{4}$

Amerikan Oral ve Maksillofasiyal Radyoloji Akademisi'nin 2012 yılında yayımladığı durum raporunda ise implant planlamasında öncelikli olarak panoramik radyografi ve ek olarak periapikal radyografiye başvurulması gerektiği bildirilmektedir. ${ }^{5}$ Uluslararası İmplantolojistler Derneği'nin raporuna paralel olarak sinüs tabanı yükseltme, kemik grefti uygulaması gibi rekonstrüktif cerrahi işlemlerin planlandığı olgularda, travma hikayesi varlığında ve implant yerleştirilecek bölgede gömük diş mevcutsa kesitsel görüntülerin kullanılması tavsiye edilmektedir. İmplant cerrahisi sonrasında yapılan periyodik kontrollerde ise asemptomatik olgularda periapikal radyografi; geniş bir bölgenin görüntülenmesi gerekli ise panoramik radyografinin kullanılması önerilmektedir. DVT'nin ancak implant mobilitesi veya hastada duyu kaybı/değişimi gibi postoperatif komplikasyonların varlığında kullanılması vurgulanmaktadır. $^{5}$

\section{CERRAHİ}

Amerikan Oral ve Maksillofasiyal Cerrahi Derneği'nin 2016 yılında yayımladığı raporda DVT'nin cerrahi amaçlı olarak kullanılmasının önerildiği durumlar; oral ve maksillofasiyal patoloji varlığı, ortognatik cerrahi planlaması, travma hikayesi, yabancı cisim varlığının değerlendirilmesi, rekonstrüktif cerrahi planlaması, süpernümerer ve gömük diş varlığı, dental implant ve sinüs tabanı yükseltme operasyonu planlaması olarak

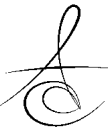


sıralanmıştır. Yukarıda sayılan durumlara kıyasla daha az sıklıkla kraniyofasiyal cerrahi planlaması, maksillofasiyal enfeksiyon varlığı, tükürük bezi patolojileri, temporomandibular eklem incelemesi ve fasiyal ağrı varlığında da kullanıldığı bildirilmiştir. ${ }^{6,7}$

\section{GÖMÜK DİŞLERİN DEĞERLENDİRİLMESİ}

Gömük maksiller ve mandibular 3.molar dişlerin çekimi sırasında yakın komşulukta bulunan mandibular kanal, maksiller sinüs gibi komşu anatomik oluşumlar ile vasküler yapılar, sert ve yumuşak dokuların hasar görme riski bulunmaktadır. Bu anatomik yapıların hasar görmesine neden olabilecek herhangi bir komplikasyon gelişimini önlemek için preoperatif cerrahi planlamanın detaylı ve dikkatli bir şekilde yapılması ve üç boyutlu anatominin değerlendirilmesi gereklidir.

\section{GÖMÜK 3.MOLAR DİŞLER}

Gömük 3. molar dişlerin çekimi öncesin- de radyografik değerlendirme için panoramik rad- yografi yıllarca "altın standart" olarak kabul edilmiştir. ${ }^{8}$ Rood ve ark. 1990 yılında panoramik radyografide gömük mandibular 3.molar diş kökleri ve mandibular kanal arasındaki ilişkiyi ve olası inferior alveolar sinir hasarı riskini gösteren 7 radyografik kriter olduğunu öne sürmüşlerdir. ${ }^{9} \mathrm{Bu}$ kriterler arasında nörosensöriyel hasar ile en fazla ilişkilendirilenler kökler üzerinde radyolüsensi varlığı, mandibular kanalın seyrinin değişme-si ve mandibular kanalın kortikal sınırının kaybıdır. ${ }^{10}$ Buna göre panoramik radyografide yukarıda adı geçen radyografik kriterlerin bir yada daha fazlasının saptanması durumunda DVT kullanılması ve koronal ile sagittal kesitlerde mandibular kanal ve diş kökleri arasındaki ilişkinin tanımlanması gerektiği vurgulanmaktadır. ${ }^{11,12}$

2019 yılında ise Avrupa Dentomaksillofasiyal Radyoloji Derneği'nin mandibular 3.molar diş çekimi öncesi DVT kullanımı ile ilgili yayımladıkları durum raporunda operasyon öncesi DVT alınmasının tedavi planlamasına katkı sağlamadığı, postoperatif inferior alveolar sinir hasarı gelişme riskini azaltmadığı ve komplikasyon gelişme riskini öngörebilme konusunda panoramik radyografiden farklı olmadığı öne sürülmektir. ${ }^{13}$ Bunun sonucunda gömük mandibular 3.molar diş çekimi öncesi rutin olarak DVT reçetelenmemesi gerektiği, DVT'nin sadece klinik muayene sonrası 2 boyutlu radyografik incelemenin yetersiz olduğu durumlarda ve olgu ile ilgili tedavi planlamasını değiştirecek bir klinik bulgu varlığında reçetelenmesi gerektiği vurgulanmaktadır. ${ }^{13}$

Gömük maksiller 3.molar dişlerin 2 boyutlu konvansiyonel radyografilerle değerlendirilmesinde karşıla- şılan anatomik süperpozisyon ve distorsiyonlar nedeniyle DVT'nin maksiller gömük dişlerin incelenmesinde kullanımının mandibular dişlere göre daha fazla yarar sağladığı ifade edilmektedir. ${ }^{14}$

\section{GÖMÜK KANİN DİŞLER}

Gömük maksiller kanin dişlerin konu- mu, komşu dişler ve çevre anatomik yapılarla ilişkisinin saptanması konvansiyonel 2 boyutlu radyografiler ile paralaks yöntemi kullanılarak yapılabilmektedir. Ancak; gömük kanin dişlerin tedavi planlamasında dişin bukkolingual pozisyonun ile angülasyonu, kök dilaserasyonu ve komşu dişlerdeki rezorpsiyon varlığının saptanması,dişin gelişim evresi gibi büyük önem taşıyan faktörlerin değerlendirilmesinde 2 boyutlu radyografiler yetersiz kalmaktadır. Yukarıda listelenen faktörlerin hem 2 boyutlu hem 3 boyutlu radyografik görüntülerle karşılaştırmalı olarak değerlendirildiği son çalışmalarda diş boyutları ve angülasyonu ile kök rezorpsiyonlarının boyutlarının tespiti açısından DVT'nin üstünlük gösterdiği bildirilmektedir. ${ }^{14}$ Buna göre; gömük kanin dişlerin operasyonu öncesinde 2 boyutlu radyografilerin yeterli anatomik bilgiyi sağlamadığı durumlarda, mümkün olan en küçük hacim seçilerek DVT kullanılması tavsiye edilmektedir. ${ }^{3}$

\section{TRAVMA}

Lokalize dentoalveolar travma sonrasında meydana gelen kök fraktürleri, dişin lüksasyonu/avülsiyonu veya lokalize alveolar fraktürlerin tanısı ve tedavi planlaması için 2 boyutlu radyografilerin yeterli bilgi sağlayamadığı durumlarda mümkün olan en küçük hacim seçilerek, yüksek çözünürlüklü DVT'nin kullanılması önerilmektedir. 3,7,15 Endodontik tedavi uygulanmış bir dişte vertikal veya horizontal fraktür şüphesi olduğunda ise kök kanalında mevcut olan kanal dolgusu ve/ veya post gibi materyallerin görüntülerde artefaktlara neden olduğu ve görüntülerin tanısal kapasitesini etkileyebileceği akılda tutulmalıdır. ${ }^{3}$

DVT, maksillofasiyal travma sonrasında meydana gelen komplike kemik fraktürlerinin saptanması ve incelenmesi için öncelikli olarak önerilmektedir. ${ }^{3}$ Ancak paranazal sinüs ve yumuşak dokuları da kapsayan travmalarda Bilgisayarlı Tomografi (BT) ve Manyetik Rezonans Görüntüleme (MRG) gibi yumuşak doku değerlendirilmesine de olanak sağlayan ileri görüntüleme sistemlerinden faydalanılabilmektedir. ${ }^{16}$ Bunlara ek olarak DVT görüntüleri yabancı cisim varlığının değerlendirilmesi ve lokalizasyonunun saptanması için de kullanılabilmektedir. 3,16

\section{MAKSİLLER SİNÜS İNCELEMELERİ}

Maksilla posterior bölgede diş çekimini takiben ve sinüs pnömatizasyonu sonucu meydana gelen ke- 
mik kaybı bölgenin implant destekli protetik rehabilitasyonunu imkânsız hale getirmektedir. Bu gibi spesifik olgularda implant yerleştirilmeden önce sinüs tabanı yükseltme operasyonu ile beraber kemik grefti uygulanması tedavi başarısını arttırmaktadır. ${ }^{17}$ Sinüs tabanı yükseltme ve kemik grefti planlanmasında sinüs ile ilişkili patoloji varlığı, Schneiderian membranının kalını̆̆ı, septa varlığı, sinüs hacmi ve açısı, sinüs ile ilişkili diş veya yabancı cisim varlığı, bölgedeki horizontal ve vertikal rezidüel kemik miktarı, bukkal kemik kalınlığı ve lateral sinüs duvarında seyreden posterior süperior alveolar arterin seyrinin değerlendirilmesi gibi bölge anatomisinin ayrıntılı ve sistematik olarak incelenmesi tedavi başarısı ve komplikasyon gelişme riski açısından önem taşımaktadır. ${ }^{18}$ Bölgenin incelenmesinde BT, DVT veya MRG gibi modern görüntüleme sistemleri kullanılabilmektedir. DVT, BT'ye kıyasla daha düşük doz ve daha yüksek çözünürlükte ile 3 boyutlu görüntüler sağladığı için bölge anatomisinin ayrıntılı incelenmesinde özellikle tercih edilmektedir. Maksiller sinüs tabanı yükseltme ve kemik grefti planlamasında 2 boyutlu radyografilerin yeterli bilgi sağlayamadığı durumlarda tanısal avantajları nedeniyle DVT kullanımı önerilmektedir.4,5,14

\section{TEMPOROMANDİBULAR EKLEM İNCELEMESİ}

DVT ile temporomandibular eklemi (TME) oluşturan kemik yapılardaki patolojik değişiklikler (osteofit, kondiler erozyon, fraktür, ankiloz vb.) ve gelişimsel anomaliler rahatlıkla izlenebilmektedir. Ancak, literatürde temporomandibular eklem ile ilgili patolojilerin çoğunlukla disk ve/veya yumuşak doku kaynaklı olduğu bildirilmektedir. $\mathrm{Bu}$ nedenle TME hastalarında DVT'nin kullanımı TME'nin kemik komponentlerine ait patolojilerin veya disfonksiyonların tanısı ve tedavi planlaması için yararlı olacağı düşünülüyorsa önerilmektedir. ${ }^{3}$

Temporomandibular eklem ile ilişkili intrakapsüler yapıların (disk anatomisi, pozisyonu ve hareketi) eklem kapsülü, çevre kas ve yumuşak dokular) incelenmesi istendiğinde MRG altın standart olarak kabul edilmektedir.3,14 Buna rağmen MR görüntülemenin TME'deki kemiğe ait değişiklikleri saptama yeteneğinin sınırlı olduğu unutulmamalıdır. ${ }^{14,19}$

Güncel çalışmaların ve sistematik analizlerin bulgularına göre TME ile ilgili patolojilerde DVT'nin MRG ile kullanılmasının her iki görüntüleme yönteminin de tanısal kapasitesini ve gözlemciler arası uyumluluğu arttırdığı ifade edilmektedir. ${ }^{20,21}$

\section{ENDODONTI}

Endodonti alanında radyografi tedavi öncesi tanısal amaçlı, tedavi sırasında (çalışma boyu tespiti vb.) ve tedavi sonrası değerlendirme için kullanılmaktadır. Endodontik tanı için öncelikli olarak önerilen görüntüleme yöntemi periapikal radyografilerdir.3,22 Periapikal radyografilerle tanı koyulamayan kompleks olgularda ise farklı açılandırmalar ile alınan grafiler (paralaks yöntemi) kullanılabilmektedir. Ancak, 2 boyutlu konvansiyonel görüntüler ile başlangıç dönemindeki periapikal lezyonlar, çevre dokular, diş kökleri ve kanal anatomisi hakkında yeterli bilgi sağlanamadığı yapılan çok sayıda çalışma ile ortaya konmuştur. ${ }^{22-25}$

2014 yılında Avrupa Endodontistler Birliği'nin yayımladığı durum raporunda endodonti hastalarında DVT kullanımı; çelişkili klinik semptomların varlığı, kompleks kanal anatomisi, tedavi komplikasyonları, klinik olarak tedavi edilebilir olarak görülen kök rezorpsiyonları,kompleks periapikal cerrahi planlaması, odontojenik kökenli olmayan patoloji varlığı gibi kompleks endodontik durumlar ile sınırlandırılmıştır. Yukarıda listelenen bu gibi durumların varlığında endodontik hastalar için DVT çekimlerinin mümkün olan en küçük hacim ve en yüksek çözünürlük seçilerek yapılması önerilmektedir. ${ }^{26}$ Dar ya da küçük görüntüleme hacminin kullanılmasının en büyük avantajı hastaya ulaşan radyasyon dozunun azalmasıdır. Buna ek olarak; görüntülenen hacim küçüldükçe, görüntü çözünürlüğü/ kalitesi dolayısı ile görüntünün tanısal kapasitesi artmaktadır. Ancak, hiçbir DVT sisteminin periapikal radyografilerden daha yüksek çözünürlükte görüntü üretemediği de akılda tutulmalıdır. ${ }^{2}$

2104 yılındaki durum raporunun yayımlanmasından sonra Avrupa Endodontistler Birliği 2019 yılında raporu yenileyerek 2014 yılındaki kompleks endodontik durumlara; kök kırıkları nedeni ile alveolar kemiklerde oluşan yıkımın değerlendirilmesi ve tamamen kalsifiye olmuş kanallarda rehber plak eşliğinde kanal tedavisi planlamasını eklemişlerdir. ${ }^{27}$

Literatürde, DVT'nin endodontik tanı ve tedavi amacıyla kullanılmasının avantajlarını bildiren çok sayıda çalışma bulunmaktadır. Ancak, dişteki metalik restorasyon ve postlar ile hacim içine giren implantlar ve kanal dolgu patları gibi dental materyallerin oluşturduğu artefaktların DVT'nin tanısal kapasitesini etkilediği vurgulanmaktadır. ${ }^{28,29} \mathrm{Bu}$ nedenle, DVT'nin rutin endodontik tanı ve tedavi planlaması amacıyla kullanılmaması gerektiği ancak tanı ve/veya tedavi planlamasına katkı sağlayacağı durumlarda DVT'ye 
başvurulması önerilmektedir. 3,22,26,27 Endodontik tanı amacıyla DVT reçetelenen hastalarda görüntülerde artefakt oluşturabilecek metal kron, post ve kanal dolgularının uzaklaştırılmasından sonra DVT çekiminin gerçekleştirilmesi tanısal kapasiteyi arttırmak açısından önemlidir. Bunun yanı sıra, mümkün olan durumlarda artefakt oluşturabilecek komşu dişlerdeki dolgu, kron gibi restorasyonların hacim dışında bırakılarak çekimin gerçekleştirilmesi sağlanmalıdır. Aksi takdirde, alınan kesit görüntüleri ile özellikle vertikal ve/veya horizontal kırık gibi yüksek çözünürlük gerektiren tanıların konulması mümkün olmayabilmektedir. 2,28,30

\section{ORTODONTI}

DVT'nin ortodontide en yaygın kullanım alanı; pozisyon anomalisine sahip gömük dişlerin konumu, komşu dişler ve çevre anatomik yapılarla iliş- kisinin saptanmasıdır. Bunlara ek olarak DVT görün- tüleri; dişin gelişim evresi, pozisyonu, dişin veya foli- külün boyutları hakkında da bilgi vermektedir. ${ }^{31,32}$

Fasiyal asimetri, dudak damak yarığı gibi dentofasiyal anomali ve deformiteli hastaların tedavi ve operasyon planlaması, diş hareketi planlanan bölgenin dentoalveolar morfolojisinin incelenmesi, özellikle kemik miktarının yetersiz olduğu sınır olgularda geçici ankraj sistemleri olan mini-plak ve vidaların yerleştirileceği bölgenin değerlendirilmesi, ortognatik cerrahi planlaması, rapid maksiller ekspansiyon planlaması ve tedavi sonuçlarının değerlendirilmesi, temporomandibular eklemin kemik komponentlerinin incelenmesi, konjenital anomali ve sendromlar, obstrüktif uyku apne sendromunda havayolu morfolojisinin değerlendirilmesi gibi klinik durumlar DVT'nin en çok kullanıldığı diğer ortodontik endikasyonlardır. ${ }^{31-34}$

Ortodontik hasta popülasyonu büyük oranda iyonize radyasyonun olumsuz etkilerine yetişkinlerden daha hassas olan çocuklardan oluşmaktadır. Bu nedenle ortodontik amaçla alınacak olan DVT'nin gerekçelendirilmesi ve hastanın maruz kalacağı iyonize radyasyonun minimize edilmesi büyük önem taşımaktadır. ${ }^{31}$ DVT'nin dentomaksillofasiyal tanı ve tedavi planlaması açısından kullanımının yaygınlaşması ile bu görüntüleme sisteminin radyasyon dozunun pediatrik popülasyonda oluşturduğu riskler ile ilişkili endişeler ortaya çıkmıştır. ${ }^{34} \mathrm{Bu}$ endişeleri gidermek, çocuklarda ve ergen hasta popülasyonunda DVT kullanımı ve dozlarını optimize etmek, DVT çekim gerekçelerini standardize etmek üzere DIMITRA (dentomaxillofacial paediatric imaging: an investigation towards low-dose radiation induced risks) adı verilen ve Avrupa'dan birçok merkezin dahil olduğu, bir proje oluşturulmuş- tur. Bu projeyi oluşturan kurul, pediatrik popülasyon için ALARA ve ALADA ilkelerinden ALADAIP (As Low as Diagnostically Acceptable being Indication-oriented and Patient-specific) yani endikasyona yönelik ve olgu spesifik bir doz optimizasyon ilkesine geçilmesini teklif etmiştir. ${ }^{35}$ Buna ek olarak; pediatrik popülasyonda uygulanacak olan görüntüleme protokolünün DVT'nin uygulama endikasyonuna, hastanın yaşı ve kilosuna bağlı olarak modifiye edilmesi gerektiği ifade edilmiştir. ${ }^{35}$

2019 yılında De Grauwe ve ark. tarafından yayımlanan sistematik derlemede; DVT'nin ortodontik olgularda kullanımı özellikle 2 boyutlu görüntülerin yetersiz kaldığı komplike olgularda veya tedavi planlamasına katkıda bulunacağı düşünülen durumlarda ve hiçbir koşulda rutin tanısal yöntem olarak kabul edilmemesi gerektiği ifade edilmektedir. ${ }^{32}$ Buna ek olarak; literatürde pediatrik popülasyonda DVT kullanımı ile ilişkili gerekçelendirme ve doz optimizasyonu konusunda hala yeterli bilginin mevcut olmadığı ve pediatrik popülasyonda DVT kullanımına karar verirken DIMITRA projesinde yer alan prensiplere uyulması gerekliliği ifade edilmektedi. ${ }^{32}$

\section{HAVA YOLU DEĞERLENDİRİLMESİ}

Obstrüktif Uyku Apne Sendromu (OUAS), uyku sırasında üst solunum yolu-özellikle orofarenkstemeydana gelen fonksiyonel obstrüksiyon ile karakterize bir sendromdur. ${ }^{36,37}$ Tekrarlayan total veya parsiyel obstrüksiyonlar nedeniyle uyku sırasında hava akışı azalması veya tamamen engellenmesi sonucunda birçok olumsuz sağlık sorunları meydana gelebilmektedir. ${ }^{37}$

Maksiller gelişim yetersizliğine bağlı olarak üst çenenin geride konumlanmasının farengeal hava yolunun daralmasına dolayısıyla OUAS gelişmesine neden olabildiği bildirilmektedir. ${ }^{3}$ Farengeal hava yolunun daralması çocuklarda ağız solunumunun gelişmesine ve dolayısıyla vertikal maloklüzyonlara yol açmaktadır. ${ }^{33}$

Maksiller gelişim yetersizliği durumunda başvurulan rapid maksiller ekspansiyon tedavisinin nazal kavite hacminin genişlemesine ve dilin daha anteriorda konumlanmasına bağlı olarak orofarengeal hava boşluğunun genişlemesi ile özellikle çocuk hastalarda OUAS semptomlarının gerilediğini bildiren çok sayıda çalışma bulunmaktadır. 38,39,40

Konvansiyonel 2 boyutlu lateral sefalografiler, sagittal düzlemde havayolu daralması tanısının konulmasında yeterli bir görüntüleme yöntemi olarak kabul edilmektedir ve ortodontik tedaviyi takiben meydana gelen havayolu değişikliklerinin saptanması için sıklıkla 
kullanılmaktadır. ${ }^{33}$ Medikal alanda ise hava yolunun tümünü görüntülemek için MRG, sine-MRG, multidedektör BT, BT, endoskopi ve optik koherens tomografi görüntülerine başvurulmaktadır. ${ }^{41,42}$ Bu ileri görüntüleme yöntemleri havayolunun değerlendirilmesinde başarılı olsa da, havayolunun 3 boyutlu rekonstrüksiyonu ve kesitsel görüntülerini medikal BT'den daha az radyasyon dozu ile daha kısa sürede (<20 sn.) sağlayan DVT'nin kullanımı yaygınlaşmaktadır. 33,41,42

Kesitsel DVT görüntüleri ile havayolu obstrüksiyonunu, retroglossal ve retrofarengeal havayolu daralmalarının lokalizasyonunu saptanabilmektedir. ${ }^{33}$ Buna ek olarak; havayolunun ortalama anteroposterior ve transversal mesafesi, total hava yolu hacmi, hava yolunun minimum kesitsel alanı, hava yolunun uzunluğu gibi parametreler de DVT görüntüleri üzerinde tespit edilebilmektedir. ${ }^{34,42}$

Ancak, DVT çekimi sırasında hastaların farklı baş ve dil pozisyonundan kaynaklanan hata- ları önlemek ve ölçümlerin tekrarlanabilirliğini sağla- mak için OUAS hastalarında uygulanması gereken bir standart protokol oluşturulması gerektiği ifade edilmektedir. ${ }^{38}$

\section{PERİODONTOLOJİ}

Radyografik görüntüler periodontal hastalıkların tanı, tedavi planlaması ve tedavi sonrası değerlendirilmesinde kullanılan önemli tanısal araçlardır. Bu amaçla en sık kullanılan konvansiyonel 2 boyutlu radyografik görüntüleme sistemleri paralel teknik ile alınan periapikal radyografi, bite-wing ve panoramik radyografilerdir. 43,44

Güncel literatür klinik periodontal parametreler ile tüm ağız periapikal radyografilerin değerlendirilmesini periodontal tanı ve tedavi planlaması için "altın standart" olarak kabul etmektedir. ${ }^{45,46}$ Fakat bu görüntüleme protokolünde hastaya ulaşan yüksek dozda radyasyon almaktadır. Bu dezavantajı ortadan kaldırmak için daha geniş görüntüleme alanına sahip olan panoramik radyografiyle beraber 4'ten az sayıda olmak üzere periapikal radyografi kullanılması önerilmiştir. ${ }^{47}$

Panoramik radyografi, tüm ağızdan alınan periapikal radyografiye kıyasla daha düşük radyasyon dozu ve tek bir görüntüde tüm dentoalveolar yapılara ait bilgi sağlaması gibi avantajlara sahip olmasına rağmen görüntüde meydana gelen distorsiyon, magnifikasyon ve süperpozisyon gibi tekniğe bağlı artefaktlar nedeniyle lokalize bölgelerdeki periodontal yıkımın tanısı açısından kapasitesi ve görüntü kalitesi intraoral radyografilerden daha düşüktür. ${ }^{43}$ Ancak, generalize periodontitis olgularında tüm bölgelerdeki alveolar kemik seviyesini saptamak üzere sıklıkla panoramik radyografiler tercih edilmektedir.

Ayrıntılı bir anamnez ve klinik inceleme sonrasında periodontitis bulguları izlenen hastadan alınan radyografiler ile; lokalize alveolar kemik miktarı, kemik kaybının yapısı, kemik içi defektlerin ve dişlerin furkasyon bölgesindeki kemik kaybı varlığı, periapikal lezyon varlığı, endoperiodontal lezyonlar, dişlerin kron ve kök uzunluğu ve morfolojisi hakkında tanı ve tedavi planlaması üzerinde etkili bulgular elde edilmektedir. Bunlara ek olarak; periodontal hastalık ile ilişkili predispozan faktörler olan aproksimal bölgedeki supra ve subgingival diş taşlarının, hijyenik olmayan restoratif ve protetik restorasyonların saptanmasında da yarar sağlamaktadır. ${ }^{45}$

Ancak, 2 boyutlu konvansiyonel radyografiler ilgili bölgede \%30 ile 50 arasında mineral kaybı olduğunda alveolar kemikteki yıkımı gösterebilmektedir. ${ }^{48}$ Dolayısıyla periodontal hastalığın erken döneminde meydana gelen kemik değişiklikleri 2 boyutlu radyografilerde izlenememektedir. Bunlara ek olarak; 3 boyutlu anatomik yapıların 2 boyutlu görüntüsü elde edildiğinde süperpozisyonlara bağlı olarak mevcut kemik defektinin maskelenebildiği veya defektin boyutlarının olduğundan daha küçük gözlendiği bilinmektedir. ${ }^{44}$

Klinik muayene ve konvansiyonel radyografik yöntemlerin uygun tanı ve tedavi planı için yetersiz olduğu olgularda anatomik süperpozisyonlar olmadan 3 boyutlu görüntülerin elde edilebildiği ve uygun parametreler ile ışınlama yapıldığı durumda tüm ağızdan alınan periapikal radyografilerden daha az doz ile üç boyutlu görüntüleme kullanılması gündeme gelmektedir. ${ }^{44}$

2017 yılında Amerikan Periodontoloji Akademisi tarafından yayımlanan Kanıta Dayalı Ortak Bildiride; DVT'nin periodontal hastalıkların tanı ve tedavi planlamasında 2 boyutlu konvansiyonel radyografinin yerini almasının ve rutin olarak kullanımımın uygun olmadığı ifade edilmiştir. ${ }^{46} \mathrm{Bu}$ rapora göre; alternatif tedavi olarak implant planlanan ileri derecede furkasyon tutulumu olan dişlerin değerlendirilmesinde, maksiller sinüs ve inferior alveolar kanala kadar uzanan ileri kemik yıkımı varlığında, klinik muayene ve konvansiyonel radyografik inceleme sonucunda tanı koyulamayan kök fraktürü, kök rezopsiyonu veya endoperiodontal lezyon şüphesi varlığında, lokalize periodontal tedaviye cevap vermeyen ve tedavi tekrarı gerektiren olgularda, periimplantitisin tanı ve tedavi planlamasına katkıda bulunacağı düşünülen olgularda müm- 
kün olan en küçük görüntü hacmi seçilerek DVT kullanılması önerilmektedir. ${ }^{46}$

2016 yılında Walter ve ark. tarafından yayımlanan derlemede DVT görüntülerinin vertikal kemik defektlerin tanısında ve morfolojisinin değerlendirilmesinde yararlı olduğu; buna ek olarak özellikle furkasyon tutulumunun mevcut olduğu maksiller molar dişlerde defektin ve çevre periodontal dokuların morfolojisinin değerlendirilmesinde yüksel tanısal kapasiteye sahip olduğu ifade edilmiştir.49 2018 yılında Woelber ve ark. ise; DVT görüntülerinin rejeneratif periodontal cerrahi prosedürler için ve maksiller molar dişlerin furkasyon defektlerinin tedavisinde yardımcı ve destekleyici bir rolü olduğu belirtmişlerdir. ${ }^{50}$

\section{DOZ}

DVT'nin dentomaksillofasiyal alanda tanı ve tedavi planlaması amacıyla kullanımının yaygınlaşması ile bu görüntüleme sisteminde hastaya ulaşan radyasyon dozu ile ilgili tartışmalar yoğunlaşmıştır. Bu nedenle DVT çekimi öncesinde mutlaka her olgu için spesifik olarak yarar/zarar değerlendirmesinin yapılması ve sadece tanıya ve/veya tedavi planlamasına katkı sağlayacak durumlarda DVT çekimi reçetelenmesi önerilmektedir. ${ }^{3}$ Hastaya ulaşan dozu minimize etmek ve ALADA kurallarına uymak amacıyla, mümkün olan en küçük görüntüleme hacminin ve tanısal açıdan yeterli kalitede görüntü eldesini sağlayacak ışınlama parametrelerinin tercih edilmesi vurgulanmaktadır. ${ }^{3}$ Işınlama parametrelerinin standart olarak uygulandığı durumlarda görüntülenen hacmin çapı ve yüksekliği arttıkça hastaya ulaşan radyasyon dozunun da arttığı belirtilmektedir.3,51 Alt ve üst çene dentoalveolar bölgenin birlikte görüntülenebildiği $10 \mathrm{~cm}$ 'den küçük hacim görüntülemelerinde ortalama efektif dozun 11$674 \mu \mathrm{Sv}$ arasında, bütün kraniyofasiyal yapıları içine alan, $10 \mathrm{~cm}$ 'den büyük hacimlerin görüntülemesinde ise ortalama efektif dozun 30-1073 $\mu \mathrm{Sv}$ değerleri arasında olduğu bildirilmektedir. ${ }^{3}$

\section{SONUC}

Diş hekimliğinin farklı disiplinlerinde DVT'nin kullanım alanları ile ilişkili yayımlanan güncel durum raporlarına göre;

- DVT'nin implant planlamasında; 2 boyutlu konvansiyonel radyografi yöntemlerinin yetersiz olduğu bilgisayar destekli planlama gerektiren olgular, kemik grefti veya sinüs yükseltme gibi rekonstrüktif cerrahi işlemlerin planlandığı olgular ile kemik miktarının yetersiz olduğu ve kritik anatomik komşuluk varlığında kullanılması önerilmektedir.
- DVT'nin gömük diş operasyonu öncesinde; klinik muayene sonrası olgu ile ilgili tedavi planlamasını değiştirecek bir klinik bulgu varlığında, 2 boyutlu radyografik incelemenin yetersiz olduğu durumlarda, gömük dişlerin anatomik komşulukları ve komşu diş köklerinde rezorpsiyon varlığının değerlendirilmesinde önerilmektedir.

- Maksillofasiyal travma sonrasında DVT kullanımı komplike kemik fraktürlerinin saptanması ve yumuşak doku incelemesinin gerekli olmadığı olgularda önerilmektedir.

- TME patolojilerinde DVT'nin kullanımı TME'nin kemik komponentlerine ait bir bulgu/patoloji varlığında veya disfonksiyonların tanısı ve tedavi planlaması açısından değiş̧iklik oluşturacağı düşünülüyorsa önerilmektedir.

- Endodontik amaçlı DVT kullanımı; çelişsili klinik semptomların varlığı, kompleks kanal anatomisi, tedavi komplikasyonları, kök rezorpsiyonları, periapikal cerrahi planlaması, odontojenik kökenli olmayan patoloji varlığı, kök kırıkları nedeni ile alveolar kemiklerde oluşan yıkımın değerlendirilmesi ve tamamen kalsifiye olmuş kanallarda rehber plak eşliğinde kanal tedavisi planlaması gibi kompleks endodontik durumlar varlığında önerilmektedir.

- DVT'nin ortodontik olgularda kullanımı özellikle 2 boyutlu görüntülerin yetersiz kaldığı iskeletsel ortodontik anomali varlığında, ortodontik tedaviye eşlik etmesi gereken cerrahi tedavi planlamasına katkıda bulunacak ise kullanılması önerilmektedir. Özellikle çocuk hastalarda DVT kullanımına karar verirken hastaya ve endikasyona özel ışınlama kurallarına uyulması gerekliliği vurgulanmaktadır.

- Havayolu obstrüksiyonu ve havayolu daralmalarının lokalizasyonu, havayolunun ortalama anteroposterior ve transversal genişliği, total hava yolu hacmi, hava yolunun minimum kesitsel alanı, hava yolunun uzunluğu DVT görüntüleri ile saptanabilmektedir. Ancak, henüz bu amaçla DVT çekimi sırasında uygulanacak bir standart protokol oluşturulmamıştır. Buna rağmen her farklı olguda olduğu gibi DVT'nin ancak hastalığın tanısı, tedavi planlaması ve/ veya tedavinin prognozuna katkı sağlayacak durumlarda kullanılması gerektiği unutulmamalıdır.

- DVT'nin periodontal kemik seviyesinin görüntülenmesinde rutin olarak kullanılmaması gerektiği bildirilmektedir. Alternatif tedavi olarak implant planlanan, ileri derecede furkasyon tutulumu olan dişlerin değerlendirilmesinde, kemik yıkımının önemli anatomik yapılara kadar uzanan olgularda, klinik muayene ve

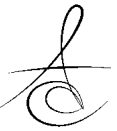


konvansiyonel radyografik inceleme sonucunda saptanamayan kök fraktürü, kök rezopsiyonu veya endoperiodontal lezyon şüphesi varlığında, periodontal tedaviye cevap vermeyen ve tedavi tekrarı gerektiren olgularda, periimplantitisin tanı ve tedavi planlamasına katkısı olacak ise DVT kullanılması önerilmektedir.

Bu çalışma, çalışmayı yürüten tüm yazarlar tarafindan okunmuş ve onaylanmış orijinal bir çalışmadır. Herhangi bir yazar, kurum ya da kuruluş ile çıkar çatışması olmadığını belirtilmek isteriz.

\section{KAYNAKLAR}

1. Mozzo P, Procacci C, Tacconi A, Martini PT, Andreis IA. A new volumetric CT machine for dental imaging based on the cone-beam technique: preliminary results. Eur Radiol 1998; 8:1558-64.

2. Baksı Şen BG, Şener E. Konik ışınlı bilgisayarlı tomografi ve endodontik uygulamalar. Kamburoğlu K, editör. Dentomaksillofasiyal Konik Işınlı Bilgisayarlı Tomografi: Temel Prensipler, Teknikler ve Klinik Uygulamalar. 1. Baskı. Ankara: Türkiye Klinikleri; 2019. s.106-18.

3. The SEDENTEXCT Project. Radiation protection: cone beam CT for dental and maxillofacial radiology. Evidence based guidelines. Geneva, Switzerland: European Commission; 2011.

4. Benavides E, Rios HF, Ganz SD, An CH, Resnik R, Reardon GT, Feldman SJ, Mah JK, Hatcher D, Kim MJ, Sohn DS, Palti A, Perel ML, Judy KW, Misch CE, Wang $\mathrm{HL}$. Use of cone beam computed tomography in implant dentistry: the International Congress of Oral Implantologists consensus report. Implant Dent 2012; 21:78-86.

5. Tyndall DA, Price JB, Tetradis S, Ganz SD, Hildebolt C, Scarfe WC; American Academy of Oral and Maxillofacial Radiology. Position statement of the American Academy of Oral and Maxillofacial Radiology on selection criteria for the use of radiology in dental implantology with emphasis on cone beam computed tomography. Oral Surg Oral Med Oral Pathol Oral Radiol 2012; 113:817-26.

6. Carter JB, Stone JD, Clark RS, Mercer JE. Applications of Cone-Beam Computed Tomography in Oral and Maxillofacial Surgery: An Overview of Published Indications and Clinical Usage in United States Academic Centers and Oral and Maxillofacial Surgery Practices. J Oral Maxillofac Surg 2016; 74:668-79.

7. Kim IH, Singer SR, Mupparapu M. Review of cone beam computed tomography guidelines in North America. Quintessence Int 2019; 50:136-145.
8. Nakagawa $\mathrm{Y}$, Ishii $\mathrm{H}$, Nomura $\mathrm{Y}$, Watanabe NY, Hoshiba D, Kobayashi K, Ishibashi K. Third molar position: reliability of panoramic radiography. J Oral Maxillofac Surg 2007; 65:1303-8.

9. Rood JP, Shehab BA. The radiological prediction of inferior alveolar nerve injury during third molar surgery. Br J Oral Maxillofac Surg 1990; 28:20-5.

10. Gilvetti C, Haria S, Gulati A. Is juxta-apical radiolucency a reliable risk factor for injury to the inferior alveolar nerve during removal of lower third molars? Br J Oral Maxillofac Surg 2019; 57: 430-4.

11. Tantanapornkul W, Okouchi K, Fujiwara $\mathrm{Y}$, Yamashiro M, Maruoka $\mathrm{Y}$, Ohbayashi N, Kurabayashi T. A comparative study of cone-beam computed tomography and conventional panoramic radiography in assessing the topographic relationship between the mandibular canal and impacted third molars. Oral Surg Oral Med Oral Pathol Oral Radiol Endod 2007; 103:2539.

12. Ghaeminia H, Meijer GJ, Soehardi A, Borstlap WA, Mulder J, Vlijmen OJ, Bergé SJ, Maal TJ. The use of cone beam CT for the removal of wisdom teeth changes the surgical approach compared with panoramic radiography: a pilot study. Int J Oral Maxillofac Surg 2011; 40:834-9.

13. Matzen LH, Berkhout E. Cone beam CT imaging of the mandibular third molar: a position paper prepared by the European Academy of DentoMaxilloFacial Radiology (EADMFR). Dentomaxillofac Radiol 2019; 48: 20190039.

14. Weiss R 2nd, Read-Fuller A. Cone Beam Computed Tomography in Oral and Maxillofacial Surgery: An Evidence-Based Review. Dent J (Basel) 2019; 7:52.

15. AAE and AAOMR Joint Position Statement: Use of Cone Beam Computed Tomography in Endodontics 2015 Update. Oral Surg Oral Med Oral Pathol Oral Radiol 2015; 120:508-12.

16. Shintaku WH, Venturin JS, Azevedo B, Noujeim M. Applications of cone-beam computed tomography in fractures of the maxillofacial complex. Dent Traumatol 2009; 25:358-66.

17. Lozano-Carrascal N, Salomó-Coll O, Gehrke SA, Calvo-Guirado JL, Hernández-Alfaro F, GargalloAlbiol J. Radiological evaluation of maxillary sinus anatomy: A cross-sectional study of 300 patients. Ann Anat 2017; 214:1-8.

18. Tavelli L, Borgonovo AE, Re D, Maiorana C. Sinus presurgical evaluation: a literature review and a

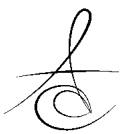


new classification proposal. Minerva Stomatol 2017; 66:115-31.

19. Alkhader M, Ohbayashi N, Tetsumura A, Nakamura $\mathrm{S}$, Okochi K, Momin MA, Kurabayashi T. Diagnostic performance of magnetic resonance imaging for detecting osseous abnormalities of the temporomandibular joint and its correlation with cone beam computed tomography. Dentomaxillofac Radiol 2010; 39:270-6.

20. Hussain AM, Packota G, Major PW, Flores-Mir C. Role of different imaging modalities in assessment of temporomandibular joint erosions and osteophytes: a systematic review. Dentomaxillofac Radiol 2008; 37:63-71.

21. Al-Saleh MA, Punithakumar $K$, Lagravere $M$, Boulanger $\mathrm{P}$, Jaremko JL, Major PW. ThreeDimensional Assessment of Temporomandibular Joint Using MRI-CBCT Image Registration. PLoS One 2017; 12:e0169555.

22. Special Committee to Revise the Joint AAE/AAOMR Position Statement on use of CBCT in Endodontics. AAE and AAOMR Joint Position Statement: Use of Cone Beam Computed Tomography in Endodontics 2015 Update. Oral Surg Oral Med Oral Pathol Oral Radiol 2015; 120:508-12.

23. Yi J, Sun Y, Li Y, Li C, Li X, Zhao Z. Cone-beam computed tomography versus periapical radiograph for diagnosing external root resorption: A systematic review and meta-analysis. Angle Orthod 2017; 87:328-37.

24. Davies A, Mannocci F, Mitchell P, Andiappan M, Patel $S$. The detection of periapical pathoses in root filled teeth using single and parallax periapical radiographs versus cone beam computed tomography - a clinical study. Int Endod J 2015; 48:582-92.

25. Patel S, Patel R, Foschi F, Mannocci F. The Impact of Different Diagnostic Imaging Modalities on the Evaluation of Root Canal Anatomy and Endodontic Residents' Stress Levels: A Clinical Study. J Endod 2019; 45:406-13.

26. European Society of Endodontology, Patel $S$, Durack C, Abella F, Roig M, Shemesh $H$, Lambrechts P, Lemberg K. European Society of Endodontology position statement: the use of CBCT in endodontics. Int Endod J 2014; 47:502-4.

27. Patel S, Brown J, Semper M, Abella F, Mannocci F. European Society of Endodontology position statement: Use of cone beam computed tomography in Endodontics: European Society of
Endodontology (ESE) developed by. Int Endod J 2019; 52:1675-8.

28. Patel S, Brown J, Pimentel T, Kelly RD, Abella F, Durack $C$. Cone beam computed tomography in Endodontics- a review of the literature. Int Endod J 2019; 52:1138-52

29. Ertaş E , Arslan H , Çapar İ , Gök T , Ertaş H. Endodontide konik ışınlı bilgisayarlı tomografi. Atatürk Üniv Diş Hek Fakül Derg 2015; 24:113-18.

30. Talwar S, Utneja S, Nawal RR, Kaushik A, Srivastava D, Oberoy SS. Role of Cone-beam Computed Tomography in Diagnosis of Vertical Root Fractures: A Systematic Review and Metaanalysis. J Endod 2016; 42:12-24.

31. Abdelkarim A. Cone-Beam Computed Tomography in Orthodontics. Dent J (Basel) 2019; 7:89.

32. De Grauwe A, Ayaz I, Shujaat S, Dimitrov S, Gbadegbegnon L, Vande Vannet B, Jacobs R. CBCT in orthodontics: a systematic review on justification of $\mathrm{CBCT}$ in a paediatric population prior to orthodontic treatment. Eur J Orthod 2019; 4:3819.

33. Kapila SD, Nervina JM. CBCT in orthodontics: assessment of treatment outcomes and indications for its use. Dentomaxillofac Radiol 2015; 44:20140282.

34. Scarfe WC, Azevedo B, Toghyani S, Farman AG. Cone Beam Computed Tomographic imaging in orthodontics. Aust Dent J 2017; 62:33-50

35. Oenning AC, Jacobs $R$, Pauwels $R$, Stratis $A$, Hedesiu M, Salmon B; DIMITRA Research Group, http://www.dimitra.be. Cone-beam CT in paediatric dentistry: DIMITRA project position statement. Pediatr Radiol 2018; 48:308-16.

36. Bruwier A, Poirrier AL, Limme M, Poirrier R. Upper airway's 3D analysis of patients with obstructive sleep apnea using tomographic cone beam. Rev Med Liege 2014; 69:663-7.

37. Momany SM, AlJamal G, Shugaa-Addin B, Khader YS. Cone Beam Computed Tomography Analysis of Upper Airway Measurements in Patients With Obstructive Sleep Apnea. Am J Med Sci 2016; 352:376-84.

38. Di Carlo G, Saccucci M, Ierardo G, Luzzi V, Occasi F, Zicari AM, Duse M, Polimeni A. Rapid Maxillary Expansion and Upper Airway Morphology: A Systematic Review on the Role of Cone Beam Computed Tomography. Biomed Res Int 2017; 2017:5460429. 
39. Camacho M, Chang ET, Song SA, Abdullatif J, Zaghi S, Pirelli P, Certal V, Guilleminault C. Rapid maxillary expansion for pediatric obstructive sleep apnea. A systematic review and meta-analysis. Laryngoscope 2017; 127:1712-9.

40. Machado-Júnior AJ, Zancanella $E$, Crespo AN. Rapid maxillary expansion and obstructive sleep apnea: A review and meta-analysis. Med Oral Patol Oral Cir Bucal 2016; 21:e465- 9.

41. Tso HH, Lee JS, Huang JC, Maki K, Hatcher D, Miller AJ. Evaluation of the human airway using cone-beam computerized tomography. Oral Surg Oral Med Oral Pathol Oral Radiol Endod 2009; 108:768-76.

42. Guijarro-Martínez R, Swennen GR. Cone-beam computerized tomography imaging and analysis of the upper airway: a systematic review of the literature. Int J Oral Maxillofac Surg 2011; 40:1227-37.

43. Mol A. Imaging methods in periodontology. Periodontol 2000 2004; 34: 34-48.

44. Haas LF, Zimmermann GS, De Luca Canto G, Flores-Mir C, Corrêa M. Precision of cone beam CT to assess periodontal bone defects: a systematic review and meta-analysis. Dentomaxillofac Radiol 2018; 47:20170084.

45. Corbet EF, Ho DK, Lai SM. Radiographs in periodontal disease diagnosis and management. Aust Dent J 2009; 54:27-43.

46. Mandelaris GA, Scheyer ET, Evans M, Kim D, McAllister B, Nevins ML, Rios HF, Sarment D. American Academy of Periodontology Best Evidence Consensus Statement on Selected Oral Applications for Cone-Beam Computed Tomography. J Periodontol 2019; 88:939-45.

47. Molander B, Ahlqwist M, Gröndahl HG. Panoramic and restrictive intraoral radiography in comprehensive oral radiographic diagnosis. Eur J Oral Sci 1995; 103:191-8.

48. Jeffcoat MK. Radiographic methods for the detection of progressive alveolar bone loss. J Periodontol 1992; 63:367-72.

49. Walter C, Schmidt JC, Dula K, Sculean A. Cone beam computed tomography (CBCT) for diagnosis and treatment planning in periodontology: $A$ systematic review. Quintessence Int 2016; 47:2537.
50. Woelber JP, Fleiner J, Rau J, Ratka-Krüger $P$, Hannig C. Accuracy and Usefulness of CBCT in Periodontology: A Systematic Review of the Literature. Int J Periodontics Restorative Dent 2018; 38:289-97.

51. Al-Okshi A, Lindh C, Salé $H$, Gunnarsson $M$, Rohlin M. Effective dose of cone beam CT (CBCT) of the facial skeleton: a systematic review. $\mathrm{Br}$ J Radiol 2015; 88:20140658.

\section{Sorumlu Yazarın Yazışma Adresi}

Arş. Gör. Nezaket Ezgi ÖZER

E.Ü. Diş Hekimliği Fakültesi,

Ağız, Diş ve Çene Radyolojisi Anabilim Dalı, Bornova, 35100, İZMİR

Tel No: (537) 3647737

E-posta: nezgiozer@hotmail.com 